\title{
PENGARUH KEPEMILIKAN ASSETS TERHADAP TINGKAT PENDAPATAN \\ PETANI PADI DI KECAMATAN KUTA BARO KABUPATEN ACEH BESAR
}

(The effect of assets ownership to the income of rice farmers in the sub-distict of Kuta Baro Aceh Besar Regency)

\author{
Novianti $^{1}$, Zakiah $^{1}$, Romano $^{1}$ * \\ ${ }^{1}$ Program Studi Agribisnis, Fakultas Pertanian, Universitas Syiah Kuala
}

\begin{abstract}
Abstrak - Indonesia adalah negara agraris, dimana sebagian besar penduduknya bermata pencaharian sebagai petani, terutama petani padi. Kepemilikan assets terdiri dari kepemilikan lahan, kepemilikan modal, modal pinjaman dan status penguasaan lahan. Tujuan penelitian ini untuk mengetahui pengaruh kepemilikan assets (lahan, modal, modal pinjaman dan status penguasaan lahan). Lokasi penelitian ini dilakukan di Kecamatan Kuta Baro Kabupaten Aceh Besar. Pengambilan sampel yang digunakan dalam penelitian ini dilakukan secara dua tahap, tahap pertama adalah secara strata dan tahap kedua secara acak (stratified random sampling). Hasil penelitian menunjukkan bahwa pengaruh kepemilikan assets terhadap pendapatan petani padi di Kecamatan Kuta Baro Kabupaten Aceh Besar adalah lahan $\left(\mathrm{X}_{1}\right)$, modal $\left(\mathrm{X}_{2}\right)$, modal pinjaman $\left(\mathrm{X}_{3}\right)$ dan status penguasaan lahan $\left(\mathrm{X}_{4}\right)$. Hasil analisis data dengan menggunakan analisis regresi linier berganda menunjukkan bahwa, modal $\left(\mathrm{X}_{2}\right)$ dan status penguasaan $\left(\mathrm{X}_{4}\right)$ berpengaruh terhadap pendapatan petani. Sedangkan lahan $\left(\mathrm{X}_{1}\right)$ dan modal pinjaman $\left(\mathrm{X}_{3}\right)$ tidak berpengaruh terhadap pendapatan petani.
\end{abstract}

Kata kunci: Kepemilikan Assets, Pendapatan dan Status Penguasaan Lahan

\begin{abstract}
Indonesia is an agricultural country, where most people are farmers, especially rice farmers. Owners assets consist of land ownership, ownership of capital, capital loan, and land ownership. The purpose of this study to determine the effect of the ownership of assets (land, capital, capital loan and land ownership). The location of this study conducted in the subdistrict of Kuta Baro Aceh Besar Regency. The sample used in this study carried out in two stages, the first stage is to strata and the second stage randomly (stratified random sampling). The results showed that the effect of the ownership of assets on the income of rice farmers in the sub-district of Kuta Baro Aceh Besar Regency is land $\left(\mathrm{X}_{1}\right)$, capital $\left(\mathrm{X}_{2}\right)$, capital loan $\left(\mathrm{X}_{3}\right)$ and land ownership $\left(\mathrm{X}_{4}\right)$. The results of data analysis using multiple linear regression analysis showed that the capital $\left(\mathrm{X}_{2}\right)$ and the status of mastery $\left(\mathrm{X}_{4}\right)$ influence on farmers' income. While, land $\left(\mathrm{X}_{1}\right)$ and capital loan $\left(\mathrm{X}_{3}\right)$ no effect the farmers' income.
\end{abstract}

Keywords: Ownership of Assets, Revenues, Rice Farmers.

\section{PENDAHULUAN}

Sektor pertanian merupakan sektor yang sangat penting dalam pembangunan nasional karena sektor ini menyerap sumber daya manusia yang paling besar dan merupakan sumber pendapatan mayoritas penduduk Indonesia. Peranan sektor pertanian di Indonesia tidak perlu diragukan lagi. Pemerintah memberikan amanat bahwa prioritas pembangunan diletakkan pada pembangunan bidang ekonomi dengan dititik beratkan pada sektor pertanian (Soekartawi, 1995). 
Permasalahan keterbatasan modal maka perlu lebih mengoptimalkan potensi lembaga keuangan yang dapat menjadi alternatif sumber dana bagi petani dan masyarakat pedesaan. Salah satu lembaga keuangan yang dapat dimanfaatkan dan didorong untuk membiayai kegiatan perekonomian di pedesaan yang mayoritas usaha penduduknya masuk dalam segmen mikro adalah Lembaga Keuangan Mikro (LKM). Lembaga keuangan mikro memiliki kelebihan yang paling nyata, yaitu prosedurnya yang sederhana, tanpa jaminan, hubungannya yang cair dan waktu pengembalian kredit yang fleksibel. Karakteristik itu sangat sesuai dengan ciri pelaku ekonomi di perdesaan (khususnya di sektor pertanian) yang memiliki aset terbatas, tingkat pendidikan rendah dan siklus pendapatan yang tidak teratur (bergantung panen) (Ashari 2006).

Keadaan pertanian khususnya di Kabupaten Aceh Besar Kecamatan Kuta Baro, penguasaan lahan pertanian rata-rata dimiliki oleh penduduk desa di sekitar kecamatan tersebut. Karena penguasaan lahannya dikuasai oleh penduduk desa itu, maka hampir semua penduduknya memiliki lahan, dan pembagiannya pun juga secara merata, yakni setiap penduduk memperoleh pembagian yang sedikit. Untuk mengetahui luas area tanah atau lahan produktif yang ada di kawasan Kabupaten Aceh Besar, dapat dilihat pada tabel berikut ini:

Tabel 1. Luas Tanah, Luas panen, dan Produksi Tanaman Padi Sawah Menurut Kecamatan Aceh Besar Pada Tahun 2015.

\begin{tabular}{|c|l|c|c|c|}
\hline No & \multicolumn{1}{|c|}{ Kecamatan } & $\begin{array}{c}\text { Luas Tanah } \\
(\mathrm{Ha})\end{array}$ & Luas Panen (Ha) & Produksi (Ton) \\
\hline 1 & Seulimeum & 5.573 & 5.538 & 36.551 \\
\hline 2 & Montasik & 4.239 & 3.253 & 23.096 \\
\hline 3 & Indrapuri & 3.689 & 3.689 & 26.930 \\
\hline 4 & Ingin Jaya & 3.628 & 2.330 & 15.844 \\
\hline $\mathbf{5}$ & Kuta Baro & $\mathbf{3 . 5 5 1}$ & $\mathbf{2 . 1 6 3}$ & $\mathbf{1 5 . 1 4 1}$ \\
\hline 6 & Blang Bintang & 2.761 & 1.943 & 13.990 \\
\hline 7 & Kuta Cot Glie & 2.062 & 2.659 & 17.018 \\
\hline 8 & Darussalam & 1.860 & 1.680 & 10.920 \\
\hline 9 & Suka Makmur & 1.579 & 1.717 & 11.160 \\
\hline 10 & Lhoong & 1.446 & 2.486 & 17.651 \\
\hline 11 & Simpang Tiga & 1.375 & 1.408 & 9.011 \\
\hline 12 & Lhoknga & 1.240 & 954 & 8.370 \\
\hline 13 & Jantho & 932 & 1.313 & 5.724 \\
\hline 14 & Lembah Seulawah & 739 & 739 & 9.323 \\
\hline 15 & Kuta Malaka & 661 & 568 & 4.730 \\
\hline 16 & Peukan Bada & 633 & 683 & 3.408 \\
\hline 17 & Darul Kamal & 630 & 793 & 4.825 \\
\hline 18 & Darul Imarah & 350 & 338 & 2.035 \\
\hline 19 & Leupung & 295 & 300 & 2.160 \\
\hline 20 & Krueng Barona Jaya & 221 & 225 & 1.440 \\
\hline 21 & Pulo Aceh & 56 & 41 & 225 \\
\hline 22 & Baitussalam & 16 & 39 & 187 \\
\hline 23 & Mesjid Raya & 36.258 & 36.209 & 243.734 \\
\hline & Jumlah & & \\
\hline
\end{tabular}

Sumber: BPS, 2014 
Berdasarkan tabel di atas menunjukkan bahwa luas tanah untuk menanam padi atau hasil produksi di Kecamatan Kuta Baro Kabupaten Aceh Besar termasuk ke dalam kategori kelima kecamatan yang memiliki luas tanah (3.551) dari kecamatan lainnya, seperti Kecamatan Seulimeum (5.573), Montasik (4.239), Indrapuri (3.689) dan Ingin Jaya (3.628). Kelima kecamatan ini memiliki luas tanah lebih besar dibandingkan dengan kecamatan lain yang ada di Kabupaten Aceh Besar dan mampu memproduksi hasil panen terbaik di Kabupaten Aceh Besar. Namun ada juga beberapa kecamatan yang memiliki luas lahan yang masih sempit dan belum sesuai untuk dijadikan lahan untuk bertani.

Namun Di Kecamatan Kuta Baro Kabupaten Aceh Besar, sebagian besar petani memiliki lahan atau tanah yang sangat luas, yang dapat dikelola dengan baik, sehingga para petani mendapatkan pendapatan yang lebih besar. Dalam sistem kepemilikan assets berupa lahan, modal dan para petani di kecamatan ini berupaya untuk memaksimalkan penggunaannya dengan sebaik mungkin.

Kepemilikan assets petani Kuta Baro yang semakin minim juga keberadaan lahan sebagai sumber penghasilan petani yang makin berkurang karena tersaingi oleh kepentingan pembangunan yang terus meningkat apabila tidak segera ditangani dengan kebijakan yang tepat maka akan menjadi masalah pembangunan sektor pertanian. Kepemilikan assets terdiri dari kepemilikan lahan pertanian, kepemilikan modal, modal pinjaman dan status penguasaan lahan.

\section{Tujuan Penelitian}

Adapun tujuan dari penelitian ini adalah untuk mengetahui pengaruh kepemilikan assets (lahan,modal, dan status pengusaan lahan) terhadap tingkat pendapatan petani padi di Kecamatan Kuta Baro Kabupaten Aceh Besar.

\section{Kerangka Pemikiran}

Assets

Assets adalah sumber penghasilan atas usahanya sendiri, dimana karakteristik umum yang dimilikinya yaitu memberikan jasa atau manfaat di masa yang akan datang (Weygant, 2007). Assets adalah benda baik yang memiliki wujud maupun sumber daya yang dimiliki oleh perusahaan yang diharapkan diperoleh manfaat ekonomisnya (Baridwan, 2004).

Assets merupakan bentuk dari penanaman modal perusahaan, bentuk-bentuknya dapat berupa harta kekayaan atau jasa yang dimiliki perusahaan yang bersangkutan (Djarwanto ,2001). Assets dapat diartikan milik yang mempunyai nilai. Assets adalah sumber daya ekonomi yang dikuasai atau dimiliki oleh masyarakat dan mempunyai manfaat ekonomi sosial serta dapat diukur dalam satuan uang.

Assets dalam akuntansi dapat diartikan sebagai sumber-sumber ekonomi yang dimiliki perusahaan sebagai hasil kejadian atau transaksi di masa lampau dan diharapkan akan bermanfaat di masa akan datang (Soemarso,2010). Assets dapat diklasifikasikan sebagai berikut:

1. Current assets, (aktiva lancar)

Current assets adalah assets yang mudah dijadikan kas atau segera dipakai, digunakan, dikonsumsikan, diolah dan habis dalam jangka waktu periode normal atau periode satu tahun. Current assets terdiri dari:

- $\quad$ Kas (cash)

- Surat berharga atau efek- efek (marketable securities)

- Wesel tagih atau Piutang wesel (notes receivable)

- Piutang usaha atau Piutang dagang (accounts receivable)

- Persediaan (inventories) 
- Perlengkapan atau bahan habis pakai (supplies)

- Beban dibayar di muka atau perskot beban (prepaid expenses)

\section{Fixed assets, (aktiva tetap)}

Fixed asset adalah harta yang dimiliki oleh perusahaan yang dipakai lebih dari satu tahun. Fixed assets terdiri dari :

- Investasi jangka panjang

- Tangible fixed assets (aktiva tetap berwujud)

- Intangible fixed assets (aktiva tetap tidak berwujud)

- Other assets (aktiva lain-lain)

Dari teori assets diatas dapat disimpulkan bahwa kepemilikan assets dalam penelitian ini terdiri dari variabel lahan, modal, dan status penguasaan lahan. Variabel lahan dan status penguasaan lahan dapat dikelompokkan ke dalam assets tetap karena lahan adalah assets tetap yang dapat digunakan secara terus menerus. Sedangkan variabel modal dapat dikelompokkan ke dalam assets lancar karena modal adalah assets yang berbentuk uang tunai, yang dapat dipakai, digunakan, dikonsumsikan, diolah dan habis dalam jangka waktu periode normal atau periode satu tahun (Soemarso, 2010).

\section{Lahan}

Pengertian lahan dibedakan kepada unsur usahatani, lahan sebagai modal dan sebagai faktor produksi berbeda. Lahan sebagai unsur usahatani mengandung pengertian bahwa lahan tersebut berperan sebagai tempat berlangsungnya kegiatan bercocok tanaman, tidak dipersoalkan apakah lahan tersebut mempunyai pengaruh terhadap tanaman yang ditanami petani. Lahan sebagai modal tetap mengandung pengertian bahwa lahan tersebut dapat dipakai beberapa kali produksi (Rodjak, 2006).

Lahan merupakan faktor utama dalam petanian memang tidak dapat ditambah, sedangkan jumlah pertumbuhan manusia terus bertambah, akibatnya luas lahan pertanian terus menyempit. Fenomena yang terjadi adalah munculnya pembagian kepemilikan dan pengusaan lahan pertanian yang tidak merata (Purwaningsih dkk, 2008).

\section{Modal}

Modal adalah sebagian dari hasil produksi yang disisihkan untuk dipergunakan dalam produksi selanjutnya. Modal sebagai faktor produksi memiliki pengertian bahwa modal tersebut merupakan subsistem produksi usahatani, karena apabila modal tidak ada atau terganggu, maka akan mempengaruhi keseluruhan produksi yang sedang bekerja.

Modal dapat dibagi dua, yaitu modal tetap dan modal tidak tetap. Modal tetap adalah barang-barang yang digunakan dalam proses produksi yang dapat digunakan beberapa kali, meskipun barang-barang modal ini habis, tetapi tidak sama sekali terhisap dalam hasil. Modal tidak tetap adalah barang-barang yang digunakan dalam proses produksi yang hanya bisa digunakan dalam proses produksi. Biaya modal bergerak harus diperhitungkan dalam harga biaya riil, sedangkan biaya modal tetap diperhitungkan melalui penyusutan nilai (Daniel, 2004).

\section{Status Penguasaan Lahan}

Status penguasaan lahan pada pokoknya dapat dibagi menjadi tiga yaitu, pemilik penggarap (owner operator), penyewa (cash tenant), dan penyakap atau bagi hasil (share tenant). Status penguasaan lahan yang berbeda secara teoritis akan menentukan tingkat keragaman usahatani yang berbeda pula. Secara teoritis kedudukan petani penyakap palinglah lemah sehingga akan berpengaruh terhadap keragaan usahatani, tetapi secara faktual tidaklah 
tentu demikian yang disebabkan oleh berbagai faktor yang perlu diteliti lebih lanjut (Mudakir,2011).

Status petani dibedakan atas petani pemilik, berarti golongan petani yang memiliki tanah milik sendiri secara langsung mengusahakan dan menggarapnya sendiri. Petani penyewa berarti golongan petani yang mengusahakan tanah orang lain dengan jalan menyewa karena tidak memiliki tanah sendiri dan kontrak sewa tergantung pada perjanjian antara pemilik tanah dengan penyewa. Petani Status petani dibedakan atas petani pemilik, berarti golongan petani yang memiliki tanah milik sendiri secara langsung mengusahakan dan menggarapnya sendiri. Petani penyewa berarti golongan petani yang mengusahakan tanah orang lain dengan jalan menyewa karena tidak memiliki tanah sendiri dan kontrak sewa tergantung pada perjanjian antara pemilik tanah dengan penyewa. Petani penyakap ialah golongan petani yang mengusahakan tanah orang lain ( Ishak, 2008).

\section{Penelitian Terdahulu}

Menurut penelitian Mulia Sari (2012), berjudul Pengaruh Variabel Kepemilikan Aset, Pendidikan, Pekerjaan dan Jumlah Tanggungan terhadap Kemiskinan Rumah Tangga di Kecamatan Bonang Kabupaten Demak, menjelaskan tentang Kecamatan Bonang adalah salah satu kecamatan yang memiliki jumlah rumah tangga miskin cukup besar. Dalam hal ini diperlukan solusi untuk meminimalisir jumlah rumah tangga miskin di Kecamatan Bonang dengan mengetahui faktor penyebab kemiskinan yang ada pada level rumah tangga. Variabel kepemilikan aset, pekerjaan dan jumlah tanggungan berpengaruh signifikan terhadap kemiskinan rumah tangga di Kecamatan Bonang, sehingga kepemilikan aset rumah tangga, jenis pekerjaan kepala rumah tangga dan jumlah tanggungan dalam rumah tangga dapat menjadi pertimbangan untuk mengatasi masalah kemiskinan di Kecamatan Bonang.

\section{METODE PENELITIAN}

Populasi dalam penelitian ini adalah petani padi di tiga desa di Kecamatan Kuta Baro Kabupaten Aceh Besar yaitu Desa Lam Alu Raya, Desa Deyah dan Desa Cot Mancang. Adapun penentuan sampel petani dilakukan secara dua tahap, tahap pertama pemisahan populasi ke dalam strata. Sedangkan tahap kedua pengambilan sampel secara acak. Dimana teknik pengambil sampel acak berstrata (stratified random sampling), yaitu teknik pengambilan sampel dimana populasi dikelompokkan dalam strata tertentu kemudian diambil sampel secara random dengan proporsi yang seimbang sesuai dengan posisi dalam populasi. Populasi petani pada Desa Deyah sebanyak 150 orang, pada Desa Cot Mancang sebanyak 102 orang, dan pada Desa Lam Alu Raya sebanyak 125 orang. Jumlah keseluruhan populasi adalah 377 petani, yang menjadi strata pada penelitian ini adalah status penguasaan lahan. Status penguasaan lahan terbagi ke dalam 2 kategori yaitu lahan milik sendiri dan lahan penyakap (bagi hasil).

Pada tabel 2 jumlah populasi terbanyak terdapat pada Desa Deyah yaitu sebanyak 150 orang dengan sampel 15 petani. Sedangkan jumlah populasi terkecil terdapat pada desa Cot Mancang dengan jumlah populasi sebanyak 102 orang dengan sampel 10 petani. Populasi dalam penelitian ini yang diambil dalam penelitian ini adalah jumlah kk, sedangkan sampel yang di ambil adalah jumlah kk yang termasuk petani. 
Tabel 2. Jumlah Populasi Petani dan Sampel Pada Tiap 'Desa di Kecamatan Kuta Baro Kabupaten Aceh Besar.

\begin{tabular}{|c|c|c|c|}
\hline No & Nama Desa & Populasi (KK) & Sampel \\
\hline 1 & Deyah & 150 & 15 \\
\hline 2 & Cot Mancang & 102 & 10 \\
\hline 3 & Lam Alu Raya & 125 & 12 \\
\hline & Jumlah & 377 & 37 \\
\hline
\end{tabular}

Sumber: Kantor Kecamatan Kuta Baro, 2015

Metode analisis dalam penelitian ini adalah dengan menggunakan metode sebagai berikut :

Regresi Linier Berganda

Untuk mengetahui pengaruh kepemilikan assets terhadap tingkat pendapatan petani padi di Kecamatan Kuta Baro Kabupaten Aceh Besar digunakan dengan analisis regresi linier berganda. Regresi linier berganda bertujuan untuk mengetahui sejauh mana pengaruh variabel bebas (lahan, modal, modal pinjaman, dan status penguasaan lahan) terhadap variabel terikat (pendapatan).

Untuk menghitung kepemilikan assets petani digunakan model regresi linier berganda sebagai berikut :

$$
\mathrm{Y}=\mathrm{a}_{0}+\mathrm{b}_{1} \mathrm{X}_{1}+\mathrm{b}_{2} \mathrm{X}_{2}+\mathrm{b}_{3} \mathrm{X}_{3}+\mathrm{b}_{4} \mathrm{X}_{4}+\mathrm{e} \ldots . .(\mathrm{Nasir}, 2003)
$$

Keterangan :

$\begin{array}{lll}\mathrm{Y} & : & \text { Pendapatan petani (Rupiah) } \\ \mathrm{a}_{0}: & \text { Konstanta } \\ \mathrm{b}: & \text { Koefisien regresi } \\ \mathrm{X}_{1}: & \text { Lahan (Hektar }) \\ \mathrm{X}_{2}: & \text { Modal (Rupiah) } \\ \mathrm{X}_{3}: & \text { Modal Pinjaman } \\ \mathrm{X}_{4}: & \text { status Penguasaan Lahan }(0=\text { milik sendiri, } 1=\text { penyakap }) \\ \mathrm{e}: & \text { Standar error }\end{array}$

\section{HASIL DAN PEMBAHASAN}

Pada umumnya petani padi yang ada di daerah penelitian tidak semuanya memiliki status lahan garapan sendiri, sebagian kecil dari petani yang ada menjalankan usahataninya pada lahan bagi hasil. hal ini akan membantu petani yang tidak memiliki lahan sendiri dan juga membantu mengurangi pengangguran dalam masyarakat tersebut.

Tabel 3. Status Penguasaan Lahan (Milik Sendiri) di Kecamatan Kuta Baro Kabupaten Aceh Besar

\begin{tabular}{|c|l|c|c|}
\hline No. & \multicolumn{1}{|c|}{ Nama Desa } & $\begin{array}{c}\text { Status Penguasaan } \\
\text { Lahan }\end{array}$ & Rata-rata (\%) \\
\hline 1. & Deyah & 6 & 31,58 \\
\hline $\mathbf{2 .}$ & Cot Mancang & 4 & 21,05 \\
\hline $\mathbf{3 .}$ & Lam Alu Raya & 9 & 47,37 \\
\hline \multicolumn{2}{r}{ Jumlah } & $\mathbf{1 9}$ & $\mathbf{1 0 0}$ \\
\hline
\end{tabular}

Sumber : Data Primer (diolah),2016

Pada tabel diatas dapat dijelaskan bahwa dalam penelitian ini status penguasaan lahan (milik sendiri) terbanyak terdapat pada Desa Lam Alue Raya sebanyak 9 sampel yang 
memiliki lahan sendiri. Sedangkan status penguasaan lahan (milik sendiri) yang paling sedikit terdapat pada Desa Cot Mancang sebanyak 4 sampel yang memiliki lahan sendiri. Dengan memiliki status penguasaan lahan (milik sendiri) maka pendapatan petani di Kecamatan Kuta Baro lebih tinggi, sehingga variabel status penguasaan lahan (milik sendiri) mempengaruhi pendapatan petani.

Tabel 4. Status penguasaan Lahan (Penyakap) di kecamatan Kuta Baro Kabupaten Aceh Besar

\begin{tabular}{|c|l|c|c|}
\hline No & Nama Desa & $\begin{array}{c}\text { Status Penguasaan } \\
\text { Lahan }\end{array}$ & Rata-rata (\%) \\
\hline 1 & Deyah & 9 & 50 \\
\hline 2 & Cot Mancang & 6 & 33,33 \\
\hline 3 & Lam Alu Raya & 3 & 16,67 \\
\hline & Jumlah & $\mathbf{1 8}$ & $\mathbf{1 0 0}$ \\
\hline
\end{tabular}

Sumber : Data Primer (diolah), 2016

Pada tabel diatas dapat dijelaskan bahwa dalam penelitian ini status penguasaan lahan (penyakap) terbanyak terdapat pada Desa Deyah sebanyak 9 sampel yang memiliki lahan penyakap. Sedangkan status penguasaan lahan (penyakap) yang paling sedikit terdapat pada Desa Lam Alu Raya sebanyak 3 sampel yang memiliki lahan penyakap. Dengan memiliki status penguasaan lahan (penyakap) maka pendapatan petani di Kecamatan Kuta Baro lebih sedikit berkurang, sehingga variable status penguasaan lahan (penyakap) mempengaruhi pendapatan petani.

Berdasarkan hasil analisis regresi linier berganda terhadap 37 sampel, maka berikut merupakan tabel yang menunjukkan pengaruh kepemilikan asset terhadap tingkat pendapatan petani padi di Kecamatan Kuta Baro Kabupaten Aceh Besar.

Tabel 5. Hasil Analisis Pengaruh Kepemilikan Asset Terhadap Tingkat Pendapatan Petani Padi di Kecamatan Kuta Baro Kabupaten Aceh Besar

\begin{tabular}{|c|c|c|c|c|c|c|}
\hline \multicolumn{7}{|c|}{ Coefficients $^{\mathrm{a}}$} \\
\hline & \multirow[b]{2}{*}{ Model } & \multicolumn{2}{|c|}{ Unstandardized Coefficients } & \multirow{2}{*}{$\begin{array}{l}\text { Standardized } \\
\text { Coefficients } \\
\text { Beta }\end{array}$} & \multirow[b]{2}{*}{$\mathrm{T}$} & \multirow[b]{2}{*}{ Sig. } \\
\hline & & B & Std. Error & & & \\
\hline \multirow[t]{5}{*}{1} & (Constant) & $1.52 \mathrm{E} 26$ & 764.870 .457 & & 1.990 & .055 \\
\hline & Luas Lahan & 459.542 .232 & 856.324 .233 & .360 & .537 & .595 \\
\hline & Modal Sendiri & 1.098 & .108 & .782 & 10.191 & .000 \\
\hline & Modal pinjaman & -.361 & .269 & -.094 & -1.342 & 189 \\
\hline & $\begin{array}{l}\text { Status } \\
\text { Kepenguasaan } \\
\text { Lahan }\end{array}$ & 808.210 .077 & 306.919 .992 & .190 & 2.633 & .013 \\
\hline
\end{tabular}

a. Dependent Variabel: Y

Berdasarkan Tabel diatas, maka model regresi linear berganda yang didapat adalah sebagai berikut.

$\mathrm{Y}=1.52 \mathrm{E} 26+459.542 \mathrm{X} 1+1.098 \mathrm{X} 2-0,361 \mathrm{X} 3+808.210 \mathrm{X} 4$

Berdasarkan hasil regresi maka dapat disimpulkan bahwa : 
Luas lahan yang berbeda-beda menyebabkan pendapatan yang diperoleh setiap petani juga berbeda. Setelah dilakukan pengolahan data, terlihat bahwa koefisien regresi luas lahan sebesar 459,542 artinya setiap kenaikan 1 hektar luas lahan akan terjadi penurunan pendapatan petani sebesar 459,542 hektar. Maka dapat disimpulkan bahwa semakin luas lahan maka tidak menentukan semakin besar pendapatan yang di terima oleh petani.

Secara parsial (uji $\mathrm{t}$ ), hasil analisis terhadap luas lahan $\left(\mathrm{X}_{1}\right)$ diperoleh $\mathrm{t}$ hitung $=0.537$ dengan tingkat signifikan 0.595. Maka $\mathrm{H}_{0}$ diterima karena nilai peluang (signifikan) < tingkat signifikan $\alpha=5 \%(0,05)$. Artinya secara parsial terdapat tidak berpengaruh dari variabel luas lahan $\left(\mathrm{X}_{1}\right)$ terhadap pendapatan petani $(\mathrm{Y})$.

Modal yang dikeluarkan oleh setiap petani berbeda-beda tergantung luas lahan yang dimiliki. Setelah dilakukan pengolahan data, terlihat bahwa koefisien regresi modal sebesar 1,098 artinya kenaikan 1 rupiah modal akan meningkatkan pendapatan sebesar Rp 1,098. Hal ini dapat disimpulkan bahwa modal mempengaruhi pendapatan petani.

Secara parsial (uji t), hasil analisis terhadap modal $\left(\mathrm{X}_{2}\right)$ diperoleh $\mathrm{t}$ hitung $=10.191$ dengan tingkat signifikan 0.000 . Maka $\mathrm{H}_{\mathrm{a}}$ diterima karena nilai peluang (signifikan) < tingkat signifikan $\alpha=5 \%(0,05)$. Artinya secara parsial terdapat pengaruh yang signifikan dari variabel modal $\left(\mathrm{X}_{2}\right)$ terhadap pendapatan petani $(\mathrm{Y})$.

Modal pinjaman yang diberikan pada desa tersebut melalui koperasi unit desa (KUD) berupa uang pinjaman. Adapun cara petani untuk memperoleh modal pinjaman adalah dengan membangun komunitas atau kelompok tani dan memiliki usaha pertanian yang nyata. Setelah dilakukan pengolahan data, terlihat bahwa koefisien regresi modal pinjaman sebesar Rp 0.361 artinya setiap kenaikan 1 rupiah modal pinjaman akan terjadi penurunan pendapatan petani sebesar Rp 0.361. Maka dapat disimpulkan bahwa modal pinjaman tidak mempengaruhi pendapatan petani. Walaupun petani mendapatkan modal pinjaman dari KUD namun tidak menjamin pendapatan petani lebih tinggi karena pinjaman yang mereka dapatkan harus mereka bayar kembali saat panen.

Secara parsial (uji t), hasil analisis terhadap modal pinjaman $\left(\mathrm{X}_{3}\right)$ diperoleh $\mathrm{t}$ hitung $=$ 1.342 dengan tingkat signifikan 0.189. Maka $\mathrm{H}_{0}$ diterima karena nilai peluang (signifikan) < tingkat signifikan $\alpha=5 \%(0,05)$. Artinya secara parsial terhadap tidak berpengaruh secara signifikan dari variabel modal pinjaman $\left(\mathrm{X}_{3}\right)$ terhadap pendapatan petani $(\mathrm{Y})$.

Pada umumnya, petani yang memiliki lahan sendiri akan memperoleh pendapatan yang lebih banyak daripada petani yang menyewa lahan dengan sistem bagi hasil. Hal ini dikarenakan petani yang memiliki lahan sendiri tidak perlu membagi hasil taninya untuk orang lain seperti halnya petani yang menyewa lahan dengan sistem bagi hasil. Setelah dilakukan pengolahan data, status penguasaan lahan milik sendiri memiliki pendapatan sebesar Rp 808.210 lebih meningkat dibandingkan status penguasaan lahan penyakap/ bagi hasil.

Secara parsial (uji t), hasil analisis terhadap status penguasaan lahan $\left(\mathrm{X}_{4}\right)$ diperoleh $\mathrm{t}$ hitung $=2.633$ dengan tingkat signifikan 0.013. Maka $\mathrm{H}_{\mathrm{a}}$ diterima karena nilai peluang (signifikan) < tingkat signifikan $\alpha=5 \%(0,05)$. Artinya secara parsial terdapat pengaruh nyata yang signifikan dari variabel status penguasaan lahan $\left(\mathrm{X}_{4}\right)$ terhadap pendapatan petani $(\mathrm{Y})$.

Dari data hasil penelitian diperoleh bahwa luas lahan $\left(\mathrm{X}_{1}\right)$, dan modal pinjaman $\left(\mathrm{X}_{3}\right)$ tidak berpengaruh positif dan signifikan terhadap pendapatan $(\mathrm{Y})$. Modal sendiri $\left(\mathrm{X}_{2}\right)$ berpengaruh signifikan terhadap pendapatan petani padi Kecamatan Kuta Baro Kabupaten Aceh Besar. Dengan memiliki modal yang tinggi maka pendapatan petani akan tinggi, sehingga variabel modal sangat mempengaruhi pendapatan petani.

Status penguasaan lahan $\left(\mathrm{X}_{4}\right)$ berpengaruh signifikan terhadap pendapatan petani padi di Kecamatan Kuta Baro Kabupaten Aceh Besar. Dalam hal ini menunjukkan karena memiliki 
luas lahan milik sendiri memperoleh pendapatan yang tinggi dan memiliki luas lahan penyakap atau bagi hasil akan memperoleh pendapatan yang sedikit berkurang. Sehingga variabel status penguasaan lahan mempengaruhi pendapatan petani (Y).

\section{KESIMPULAN DAN SARAN}

Berdasarkan hasil penelitian dan pembahasan, maka dapat disimpulkan bahwa:

Luas lahan tidak berpengaruh secara signifikan terhadap pendapatan petani di Kecamatan Kuta Baro kabupaten Aceh Besar. Dalam penelitian ini menunjukkan bahwa ratarata petani yang memiliki luas lahan yang lebih luas tidak mengalami pendapatan lebih besar secara signifikan.

Modal berpengaruh signifikan terhadap pendapatan petani di Kecamatan Kuta Baro kabupaten Aceh Besar. Hal ini menunjukkan karena apabila modal tidak ada atau terganggu, maka akan mempengaruhi keseluruhan produksi yang sedang bekerja.

Modal pinjaman tidak berpengaruh signifikan terhadap pendapatan petani di Kecamatan Kuta Baro kabupaten Aceh Besar. Hal ini menunjukkan bahwa walaupun mendapatkan pinjaman modal dari koperasi desa, namun tidak meningkatkan pendapatan petani.

Status penguasaan lahan berpengaruh terhadap tingkat pendapatan petani. Dalam hal ini menunjukkan bahwa petani padi yang ada di daerah penelitian tidak semuanya memiliki lahan garapan sendiri, sebagian kecil dari petani yang ada menjalankan usahataninya pada lahan bagi hasil

Adapun saran :

Untuk meningkatkan pendapatan petani padi diupayakan perluasan pemilikan lahan, penyertaan modal dalam bentuk jaminan kredit usaha tani dan bantuan langsung sarana produksi.

Penelitian lebih lanjut agar menelaah pengaruh asset yang lain, kaitannya dengan pendapatan petani.

\section{DAFTAR PUSTAKA}

Ashari. 2006. Pedoman Penulisan Skripsi Fakultas Keguruan dan Ilmu Pendidikan Universitas Syiah Kuala. Darussalam. Banda Aceh.

Baridwan, Zaki. 2004. intermediate Accounting “Pengantar Akuntansi”. Buku 2. Edisi 21. Salemba Empat Jakarta.

BPS. 2014. Luas Lahan Kabupaten Aceh Besar. Badan Pusat Statistik Aceh Besar. Aceh Besar.

Daniel, M. 2002. Pengantar Ekonomi Pertanian. Bumi Aksara. Jakarta.

Djarwanto. 2004. Pokok-pokok Analisa Laporan Keuangan. Edisi kedua. Yogyakarta : BPFEYogyakarta.

Ishak. 2008. Pengolaan Perpustakaan Berbasis Teknologi Informasi. Pustaka Jurnal Studi Perpustakaan dan Informasi. Vol. 4, No. 2 pp 87. 
Nasir. 2003. Metode Analisis Kuantitatif Regresi Linier Berganda. Gramedia. Jakarta.

Sari. Ayula Candra Dewi Mulia. 2012. berjudul Pengaruh Variabel Kepemilikan Aset, Pendidikan, Pekerjaan dan Jumlah Tanggungan terhadap Kemiskinan Rumah Tangga di Kecamatan Bonang Kabupaten Demak. Skripsi. Fakultas Ekonomika dan Bisnis Universitas Diponegoro. Semarang.

Purwaningsih Yunastiti, dkk. 2008. Ketahanan Pangan: Situasi, Permasalahan, Kebijakan dan Pemberdayaan Masyarakat. Jurnal Ekonomi Pembangunan. Balai Penelitian dan Pengembangan Ekonomi Fakultas Ekonomi UniversitasMuhammadiyah Surakarta. Surakarta. Vol. 9 No.1.

Rodjak, Abdul. 2006. Manajemen Usahatani. Jilid II. Pustaka Gratuna. Bandung.

Soekartawi et.al. 1995. Analisis Usahatani. Universitas Indonesia. Jakarta.

Soemarso S.R. 2010. Akuntansi : Suatu Pengantar, cetakan keempat. Salemba empat. Jakarta.

Weygandt. dkk. 2007. Accounting Principles Pengantar Akuntansi, Edisi ketujuh, Penerbit Salemba Empat, Jakarta. 